\title{
DIGITAL DOCUMENTATION, BRIDGE DECK LINEARITY DEFORMATION AND DECK THICKNESS MEASUREMENT USING TERRESTRIAL LASER SCANNER (TLS) AND CLOSE RANGE PHOTOGRAMMETRY (CRP)
}

\author{
S.K.P.Kushwaha ${ }^{1, *}$, Hina Pande ${ }^{2}$, S. Raghavendra ${ }^{3}$ \\ ${ }^{1}$ Indian Institute of Remote Sensing, ISRO, Dehradun, India - s.k.p.kushwaha92@gmail.com, (hina, raghav)@iirs.gov.in
}

\author{
Commission V, WG V/5
}

KEY WORDS: Terrestrial Laser Scanning (TLS), Close Range Photogrammetry (CRP), Point Cloud dataset, Bridge 3D Digital Documentation, Deck Linearity deformation, Deck Thickness measurement

\begin{abstract}
:
Bridges are one of the vital and valuable engineer structure from decades. As they play a major role in the road transportation sector. Few old bridges lacks its documents about the measurements of the structure. The study has been carried out on three different types of bridges like Truss, Beam and Cable bridges. Documenting these bridges can be utilised to reconstruct or renovate the bridge in case of any disaster or damage. 3D documentation is made from the point cloud Dataset acquired from Terrestrial Laser Scanner TLS (Riegl VZ 400) and Close Range photogrammetry - CRP (Nikon DSLR 5300). TLS and CRP point cloud are merged together to increase the density of points. Over the duration of time the bridge gets older and due to the load on the bridge deck, linearity in the deck effects and this linearity deformation measurement is important to know the present deformation in the deck. To know exactly at which part there is more linearity deformation, deflection is calculated at sample intervals between the present linearity conditions of the deck to the idle linearity conditions of the deck. The bridge deck thickness is also measured with the point cloud dataset. A slice is cut through the deck of point cloud dataset, the difference between the top and bottom layer of the deck gives us the thickness of the deck including the road. This thickness can be used to measure when a new deck layer is constructed or during filling up of any potholes. This study is mainly focused to help the construction and maintenance authority, bridge monitoring department and researchers.
\end{abstract}

\section{INTRODUCTION}

Different engineering structures have different roles in the modern day to day life. Bridges play a major role in connectivity between two sides. In this study three different types of bridges are focused which are Truss Bridge, Beam Bridge and Cable Bridge. Digital documentation is very reliable method for storing the geometrical information for longer duration of time. Due to heavy traffic conditions and harsh environments bridge deterioration takes place which can be monitoring using non-contact technique like Terrestrial Laser Scanning (TLS) and Close Range Photogrammetry (CRP). Many researches has been carried out for generating photorealistic 3D models using TLS and CRP which includes documenting A'Famosa Fortress, Porta de Santiago, Malaysia, (Wei, Chin, Majid, \& Setan, 2010). Joint use of TLS and Photogrammetry is used to enhance the position of the edges and linear surface features. Also generating a 3D virtual model for documenting of Al-Khasneh, Petra, Jordan (Alshawabkeh \& Haala, 2006). An automatic approach for efficiently monitoring the status of buildings under construction like as-built dimension calculation and control can be done with the help of CAD models generated from lidar scans. The approach is made more efficient by increasing the registration quality by point matching method which uses iterative closest point (ICP) algorithm (Bosche, 2010). Bridge measurement documentation can be done with the help of TLS which is fast, safe and applicable to different weather conditions (Truong-Hong \& Laefer, 2014). An automatic approach of workflows have been used to extract the minimum under clearance of Bridges using laser point cloud data (Tang \& Akinci, 2012). A case study to find where the minimum under clearance and the geometry of a pre-stressed concrete beam is monitored with TLS and verified with total station for its accuracy in the paper (Riveiro, González-jorge, Varela, \& Jauregui, 2013). TLS has also been used to estimate Stress on a beam structure when subjected to a concentrated load and the structural responses were monitored with finite element analysis (Lee \& Park, 2011).

\section{STUDY AREA AND DATA ACQUISITION}

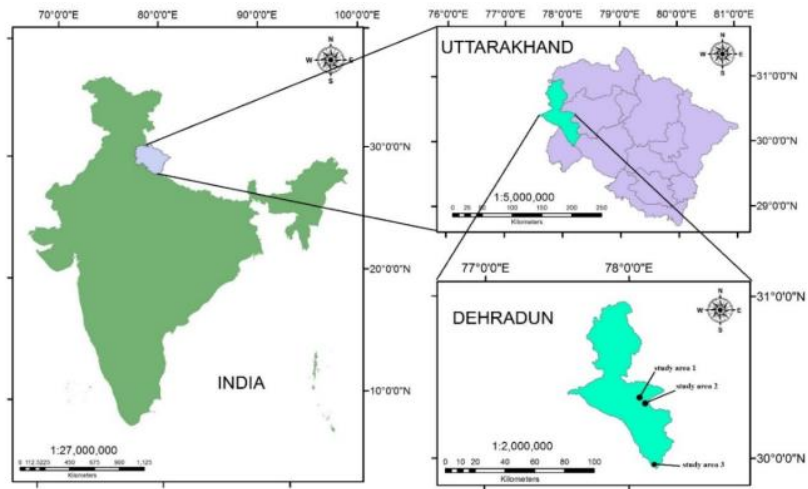

Figure 1: Study Area Map

* Corresponding author 
Three different types of bridges (Truss, Beam and Cable) were selected for this research. Their locations has been shown in the figure 1 .

All the study area and the pointcloud dataset with the number of scans and images are tabulated in the table 1 .

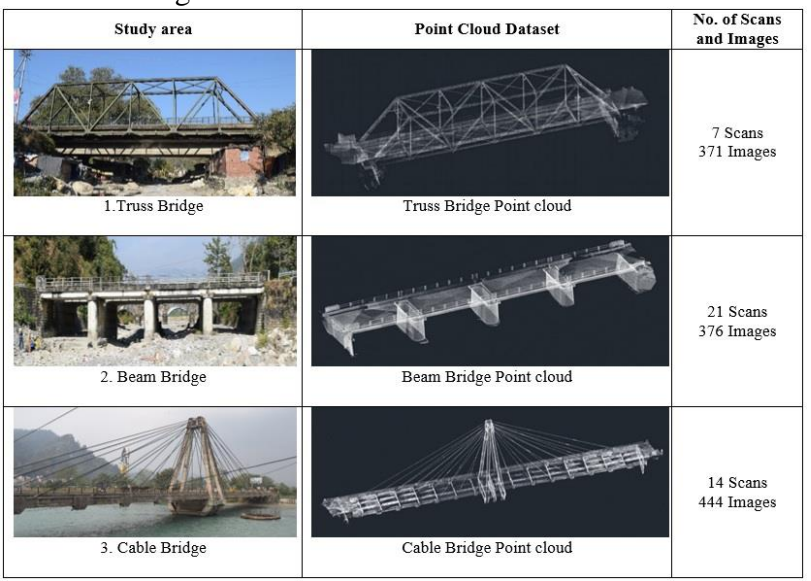

Table 1: Bridges with Point Cloud datasets and the number of scans and images acquired

\section{METHODOLOGY, INSTRUMENT'S AND SOFTWARE'S USED}

The workflow that was followed during the research has been shown in the figure 2 . The data was acquired from different scan positions. All the scans were co-registered together to form a single point cloud. Many overlapping images were captured at the study sites. All the images were aligned and Tie points were generated. Dense point cloud was generated with the help of Tie points. TLS and CRP point clouds were merged together. Noise and Outliers were filtered out from the merged point cloud. Then the required outputs were extracted. The values were validated with the help of laser distometer.

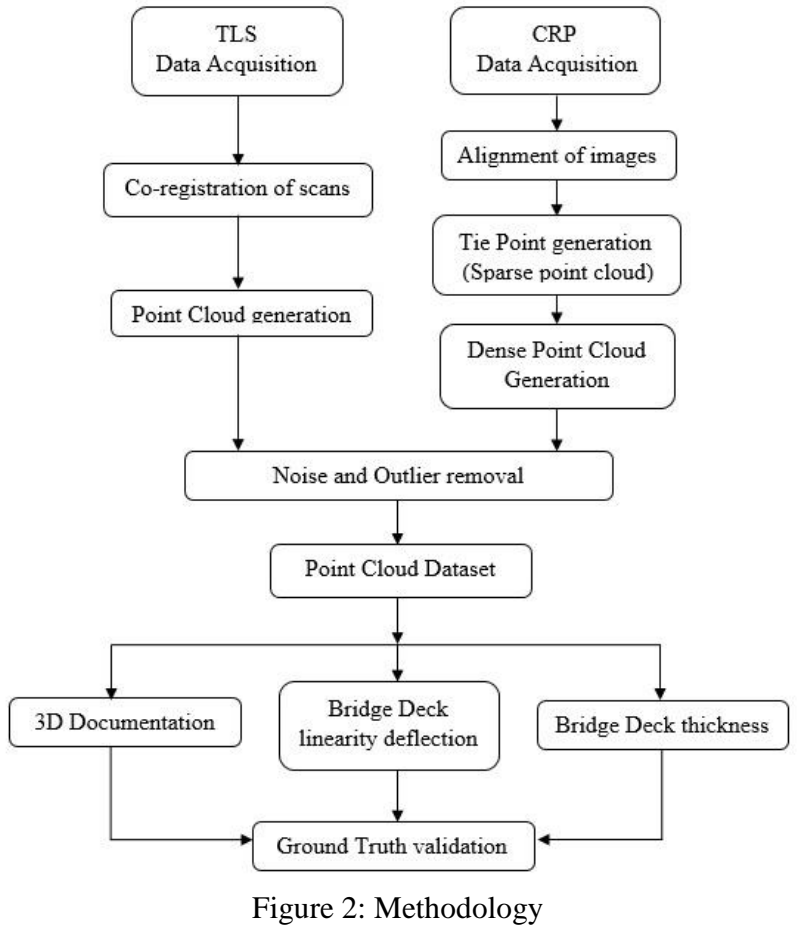

TLS Point cloud was acquired with the instrumetnent Riegl VZ 400 and RiSCAN PRO software further preprocessed in it. CRP point cloud was generated from the images in the Agisoft
Photoscan and further processed in Cloud Compare. The data was convereted into AutoCAD format with the help of ReCap software.

\begin{tabular}{|c|l|}
\hline Instrument used & \multicolumn{1}{|c|}{ Software's used } \\
\hline & RiSCAN PRO \\
Terrestrial laser Scanner - Rieg1 VZ 400 & Autodesk ReCap \\
Nikon DSLR D5300 & AutoCAD 2018 \\
Leica Distometer S910 & Agisoft Photoscan \\
& CloudCompare \\
\hline
\end{tabular}

Table 2: Instrument and Softwares used

\section{RESULTS AND DISCUSSIONS}

Drawings of different views like top, bottom, side and front were extracted from different sections of the Point cloud and validated from the measurements obtained from Laser distometer.

\subsection{Study area 1: Truss Bridge}

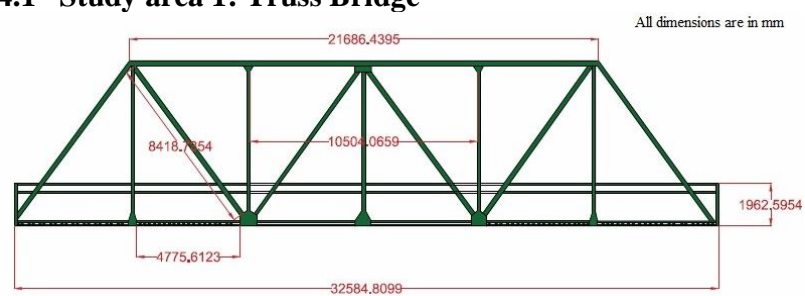

Figure 3: Side drawing of Truss Bridge

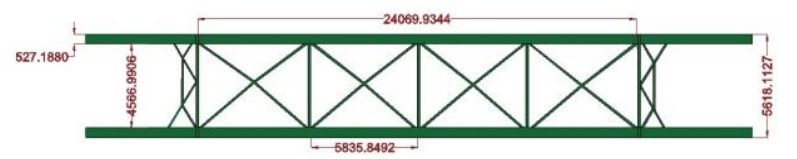

Figure 4: Top drawing of Truss Bridge

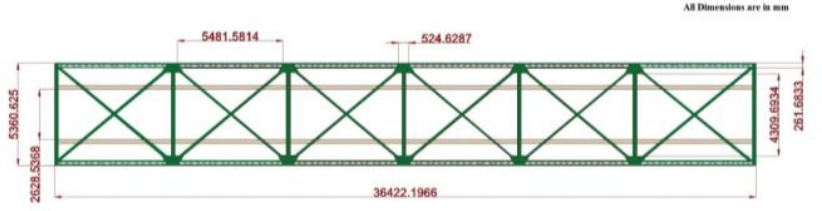

Figure 5: Bottom drawing of Truss Bridge

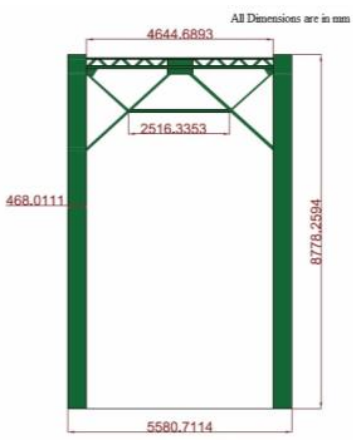

Figure 6: Front drawing of Truss Bridge

Some parts of the Truss Bridge are shown in the figure 7.

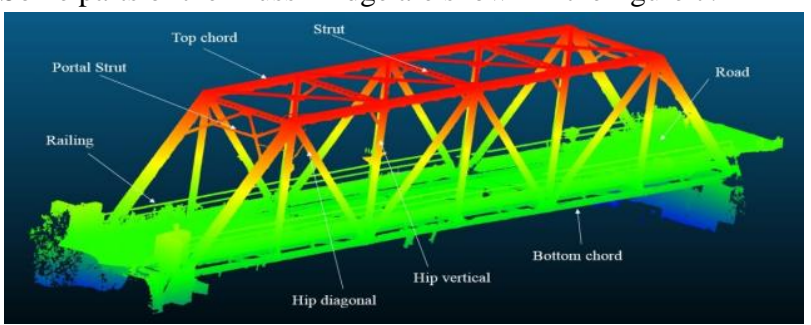

Figure 7: Parts of Truss Bridge 
The measurements obtained from the point cloud and laser distometer with their difference and the mean error obtained are tablulated in the table 3 .

\begin{tabular}{|l|c|c|c|}
\hline $\begin{array}{c}\text { Name of the } \\
\text { Bridge component }\end{array}$ & $\begin{array}{c}\text { Measurement in } \\
\text { point cloud dataset } \\
\text { (TLS+ CRP)(m) }\end{array}$ & $\begin{array}{c}\text { Measurement } \\
\text { in Laser } \\
\text { Distometer(m) }\end{array}$ & $\begin{array}{c}\text { Difference } \\
\text { between } \\
\text { Measurements(m) }\end{array}$ \\
\hline Top chord & 24.124 & 23.989 & 0.135 \\
\hline Bottom chord & 36.494 & 36.457 & 0.037 \\
\hline Hip vertical & 6.389 & 6.360 & 0.029 \\
\hline Railing & 36.559 & 36.598 & 0.039 \\
\hline Strut & 4.638 & 4.573 & 0.101 \\
\hline Portal strut & 4.680 & 4.572 & 0.108 \\
\hline Hip diagonal & 8.496 & 8.588 & 0.092 \\
\hline Road width & 4.694 & 4.705 & 0.011 \\
\hline Slab thickness & 0.458 & 0.432 & 0.026 \\
\hline Vertical Hip width & 0.109 & 0.106 & 0.003 \\
\hline Diagonal Hip width & 0.177 & 0.150 & 0.027 \\
\hline \multicolumn{2}{|r|}{ Mean in the difference of the measurements } & $\mathbf{0 . 0 5 5 2}$ \\
\hline
\end{tabular}

Table 3: comparison of measurements of Truss Bridge

The deflections in the deck linearity is measured at different sample intervals between both the ends of abutment.

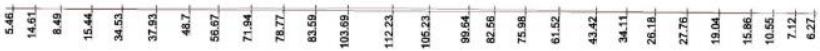

Figure 8: Truss Bridge deck linearity deflections

All the deflections obtained are shown in the graph format to easily identify the maximum deflection through out the deck. No support was present except the abutments at either ends of Truss Bridge deck.

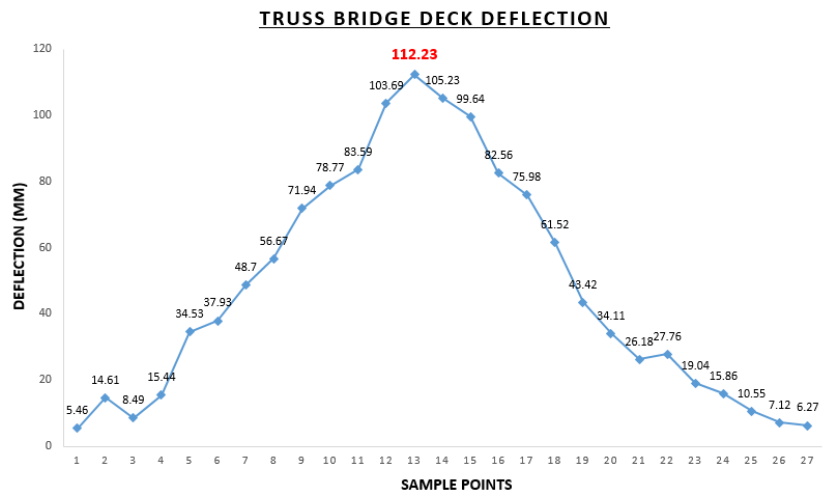

Figure 9: Truss bridge deck linearity deflection graph

The maximum Truss Bridge deck linearity deflection obtained is $112.23 \mathrm{~mm}$ shown in red.

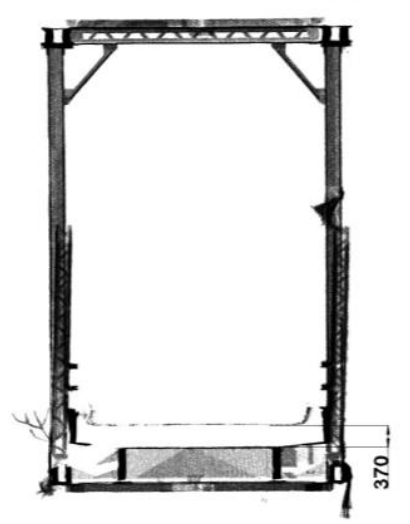

Figure 10: Bridge deck thickness of Truss Bridge

The Truss Bridge deck thickness obtained is $370 \mathrm{~mm}$.

\subsection{Study area 2: Beam Bridge}

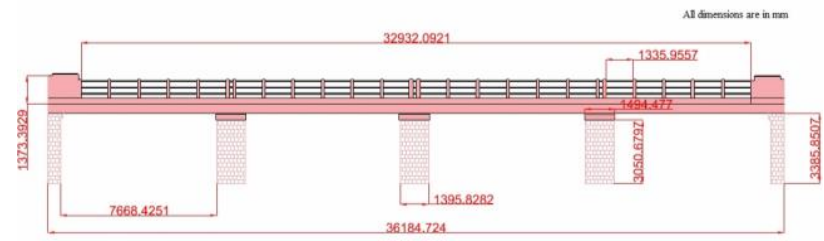

Figure 11: Side drawing of Beam Bridge

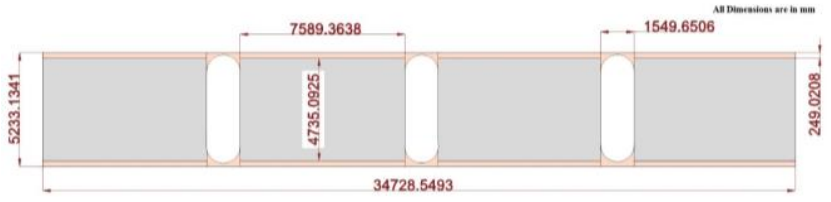

Figure 12: Bottom drawing of Beam Bridge

Some parts of the Beam Bridge are shown in the figure 13.

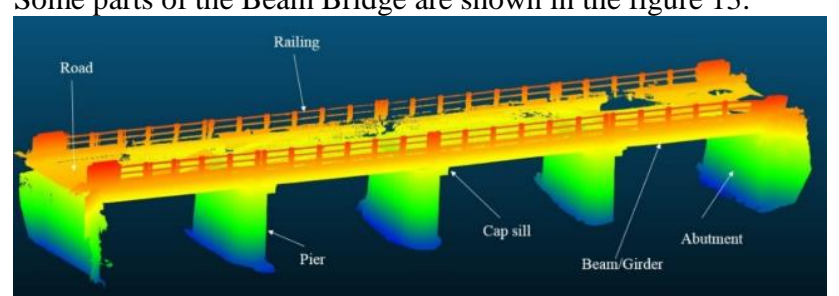

Figure 13: Parts of Beam Bridge

\begin{tabular}{|l|c|c|c|}
\hline $\begin{array}{c}\text { Name of the Bridge } \\
\text { Component }\end{array}$ & $\begin{array}{c}\text { Measurement in } \\
\text { point cloud dataset } \\
\text { (TLS + CRP)(m) }\end{array}$ & $\begin{array}{c}\text { Measurement } \\
\text { in Laser } \\
\text { Distometer(m) }\end{array}$ & $\begin{array}{c}\text { Difference } \\
\text { between } \\
\text { Measurements(m) }\end{array}$ \\
\hline Beam length & 35.951 & 35.941 & 0.010 \\
\hline Beam thickness & 0.425 & 0.413 & 0.012 \\
\hline Beam width & 3.752 & 3.698 & 0.054 \\
\hline Railing & 32.830 & 32.817 & 0.013 \\
\hline Cap sill width & 1.399 & 1.368 & 0.031 \\
\hline Cap sill thickness & 0.280 & 0.273 & 0.007 \\
\hline Cap sill length & 5.160 & 5.096 & 0.064 \\
\hline Pier width & 1.280 & 1.256 & 0.024 \\
\hline Pier height & 3.302 & 3.301 & 0.001 \\
\hline \multicolumn{2}{|r|}{ Mean in the difference of the measurements } & $\mathbf{0 . 0 2 4 1}$ \\
\hline
\end{tabular}

Table 4: comparison of measurements of Beam Bridge
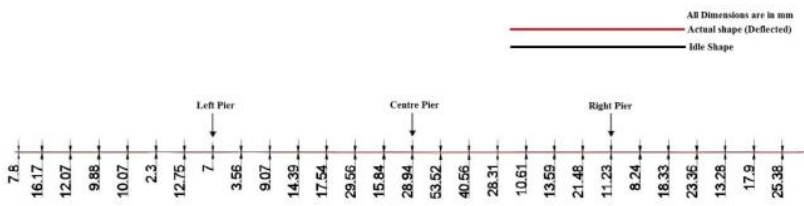

Figure 14: Beam Bridge deck linearity deflections BEAM BRIDGE DECK DEFLECTION

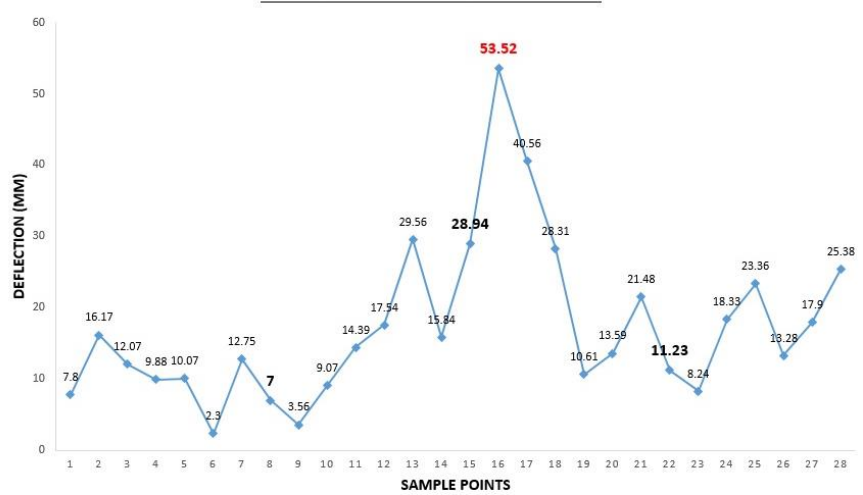

Figure 15: Beam Bridge deck linearity deflection graph 
In the figure 15 , the bold black values corresponds to the deflection at the left, centre and right piers of the Beam Bridge. The maximum Beam Bridge deck linearity deflection obtained is $53.52 \mathrm{~mm}$ shown in red at the right side of the centre pier.

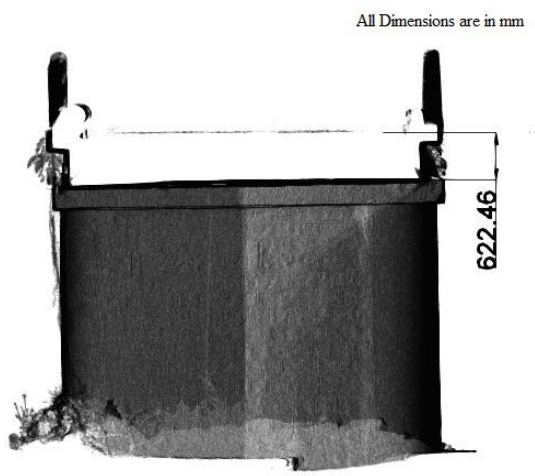

Figure 16: Bridge deck thickness of Beam Bridge

The Beam Bridge deck thickness obtained is $622.46 \mathrm{~mm}$.

\subsection{Study area 3: Cable Bridge}

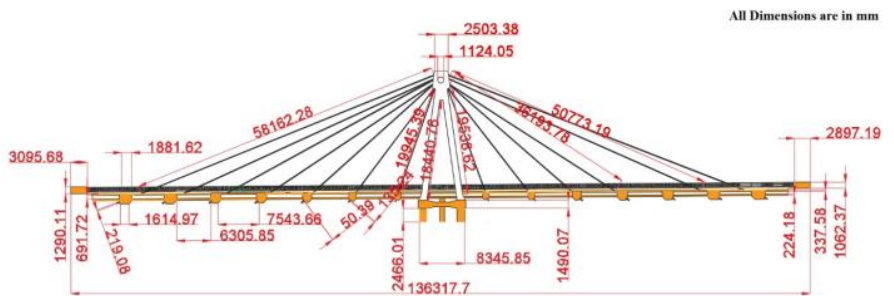

Figure 17: Side drawing of Cable Bridge

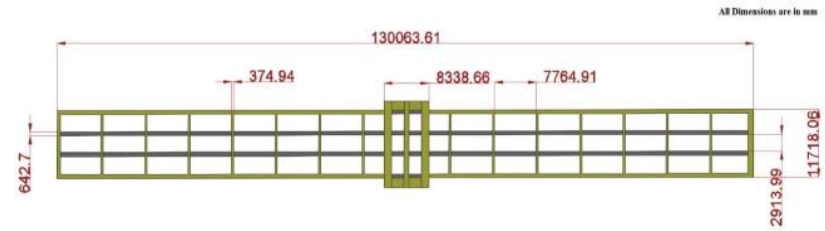

Figure 18: Bottom drawing of Cable Bridge

Some parts of the Cable Bridge are shown in the figure 19.

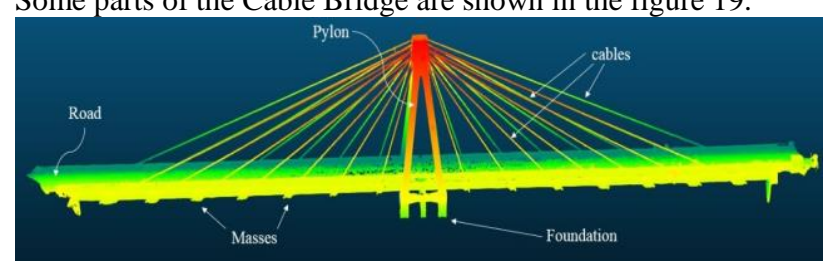

Figure 19: Parts of Cable Bridge

\begin{tabular}{|l|c|c|c|}
\hline $\begin{array}{c}\text { Name of the Bridge } \\
\text { Component }\end{array}$ & $\begin{array}{c}\text { Measurement in } \\
\text { point cloud dataset } \\
\text { (TLS + CRP)(m) }\end{array}$ & $\begin{array}{c}\text { Measurement } \\
\text { in Laser } \\
\text { Distometer(m) }\end{array}$ & $\begin{array}{c}\text { Difference } \\
\text { between } \\
\text { Measurements(m) }\end{array}$ \\
\hline Pylon height & 20.932 & 20.846 & 0.086 \\
\hline Pylon thickness & 1.051 & 1.042 & 0.009 \\
\hline Road width & 7.564 & 7.501 & 0.063 \\
\hline Foundation length & 5.352 & 5.306 & 0.046 \\
\hline Foundation height & 1.283 & 1.279 & 0.004 \\
\hline Foundation width & 8.361 & 8.343 & 0.018 \\
\hline Deck length & 130.354 & 130.329 & 0.025 \\
\hline $\begin{array}{l}\text { Distance between } \\
\text { neighbouring masses }\end{array}$ & 6.012 & 5.996 & 0.016 \\
\hline \multicolumn{2}{|c|}{ Mean in the difference of the measurements } & $\mathbf{0 . 0 3 3 3}$ \\
\hline
\end{tabular}

Table 5: comparison of measurements of Cable Bridge
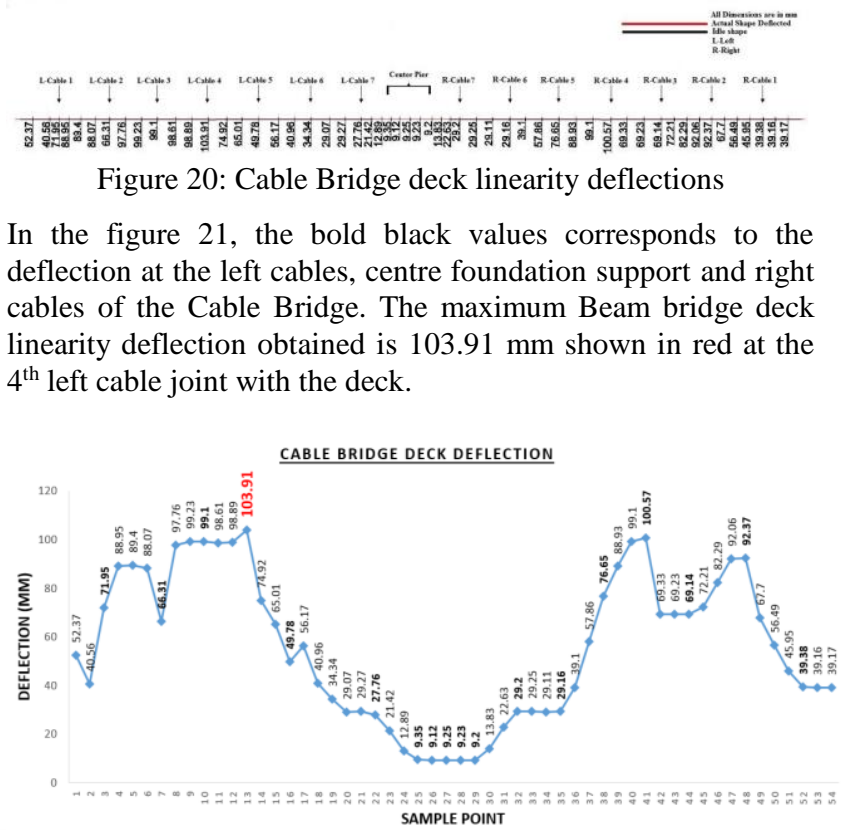

Figure 21: Cable Bridge deck linearity deflection graph

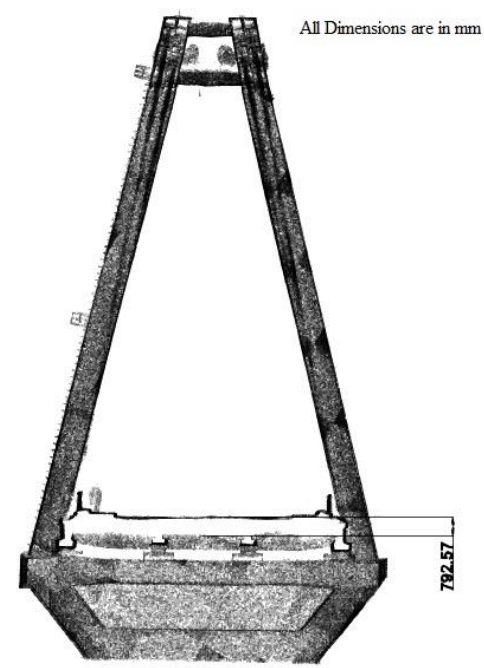

Figure 22: Bridge deck thickness of Cable Bridge

The Cable Bridge deck thickness obtained is $792.57 \mathrm{~mm}$.

\section{CONCLUSIONS}

The 3D digital documentation prepared can be stored for longer time period and can be used for reconstruction or renovation. The mean difference between the measurements obtained from the TLS and CRP point cloud dataset with the laser distometer for the Truss, Beam and Cable Bridges are $0.0552 \mathrm{~m}, 0.0241 \mathrm{~m}$ and $0.0333 \mathrm{~m}$ respectively. The deck linearity deflection can be used to monitor it timely. The maximum bridge deck linearity deflection obtained for Truss Bridge is $112.23 \mathrm{~mm}$ at the centre of the deck, Beam Bridge is $53.52 \mathrm{~mm}$ at the right side of the centre pier and Cable Bridge is $103.91 \mathrm{~mm} 4^{\text {th }}$ left cable. The deck thickness measurement is an important factor to monitor the construction of deck or when a new layer of road is to be constructed. The bridge deck thickness obtained for Truss, Beam and Cable bridges are $370 \mathrm{~mm}, 622.46 \mathrm{~mm}$ and 792.57 mm respectively. 


\section{REFERENCES}

Alshawabkeh, Y., \& Haala, N. (2006). Laser Scanning and Photogrammetry: A Hybrid Approach For Heritage Documentation.

Bosche, F. (2010). Automated recognition of 3D CAD model objects in laser scans and calculation of as-built dimensions for dimensional compliance control in construction. Advanced Engineering Informatics, 24(1), 107-118. https://doi.org/10.1016/j.aei.2009.08.006

Lee, H. M., \& Park, H. S. (2011). Gage-Free Stress Estimation of a Beam-like Structure Based on Terrestrial Laser Scanning, 26, 647-658. https://doi.org/10.1111/j.14678667.2011.00723.x

Riveiro, B., González-jorge, H., Varela, M., \& Jauregui, D. V. (2013). Validation of terrestrial laser scanning and photogrammetry techniques for the measurement of vertical underclearance and beam geometry in structural inspection of bridges. Measurement, 46(1), 784-794. https://doi.org/10.1016/j.measurement.2012.09.018

Tang, P., \& Akinci, B. (2012). Automatic execution of workflows on laser-scanned data for extracting bridge surveying goals. Advanced Engineering Informatics, 26(4), 889-903. https://doi.org/10.1016/j.aei.2012.07.004

Truong-Hong, L., \& Laefer, D. F. (2014). Application of Terrestrial Laser Scanner in Bridge Inspection: Review and an Opportunity. IABSE Symposium Report, 102(9), 2713-2720. https://doi.org/10.2749/222137814814070190

Wei, O. C., Chin, C. S., Majid, Z., \& Setan, H. (2010). 3D Documentation And Preservation Of Historical Monument Using Terrestrial Laser Scanning, 10(1), 73-90. 